\title{
Article
}

\section{A Hybrid Thermopneumatic and Electrostatic Microvalve with Integrated Position Sensing}

\author{
Joseph A. Potkay ${ }^{1}$ * and Kensall D. Wise ${ }^{2}$
}

1 Advanced Platform Technology Center, Department of Veterans Affairs Medical Center, Cleveland, OH 44106, USA

2 Department of Electrical Engineering and Computer Science, The University of Michigan, Ann Arbor, MI 48109, USA; E-Mail: wise@umich.edu

* Author to whom correspondence should be addressed; E-Mail: joseph.potkay@ case.edu; Tel.: +1-216-904-5641; Fax: +1-216-707-6420.

Received: 20 March 2012; in revised form: 17 April 2012 / Accepted: 24 April 2012 /

Published: 27 April 2012

\begin{abstract}
This paper presents a low-power hybrid thermopneumatic microvalve with an electrostatic hold and integrated valve plate position sensing. This combination of actuators in a single structure enables a high throw and force actuator with low energy consumption, a combination that is difficult to otherwise achieve. The completed $7.5 \mathrm{~mm} \times 10.3 \mathrm{~mm} \times 1.5 \mathrm{~mm}$ valve has an open flow rate of $8 \mathrm{sccm}$ at $600 \mathrm{~Pa}$, a leak rate of $2.2 \times 10^{-3} \mathrm{sccm}$ at $115 \mathrm{kPa}$, a open-to-closed fluidic conductance ratio of nearly one million, an actuation time of $430 \mathrm{~ms}$ at $250 \mathrm{~mW}$, and a required power of $90 \mathrm{~mW}$ while closed. It additionally requires no power to open, and has a built-in capacitive position sensor with a sensitivity of $9.8 \mathrm{fF} / \mathrm{kPa}$. The paper additionally presents analytical models of the valve components, design tradeoffs, and guidelines for achieving an optimized device.
\end{abstract}

Keywords: microvalve; thermopneumatic; electrostatic; low power; $\mu \mathrm{GC}$; hybrid actuator

\section{Introduction}

Most portable microfluidic analysis systems require valving systems with similar performance requirements. Specifically, the valve for such systems should consume very little power to accommodate the use of a battery, have a throw (valve plate travel distance) greater than $30 \mu \mathrm{m}$ to facilitate the passage of biological or chemical samples, be able to remain closed in the face of a large hold off pressure, and 
have a low leak rate, low dead volume, and fast response time. For the micro gas chromatography $(\mu \mathrm{GC})$ system being developed in the National Science Foundation Engineering Research Center for Wireless Integrated MicroSystems (WIMS ERC) at The University of Michigan, the required valve specifications are shown in Table 1. In the past, it has been difficult to achieve valves with a large force, high open flow rate and low power, and this was the main challenge for this work.

Table 1. Performance targets for the microvalve.

\begin{tabular}{lr}
\hline Category & Requirement \\
\hline Energy Consumption & $<50 \mathrm{~mJ} /$ transition \\
Power Consumption & $<10 \mathrm{~mW}$ average \\
Open flow rate & $>5 \mathrm{sccm} @ 500 \mathrm{~Pa}$ \\
Maximum differential pressure & $>50 \mathrm{kPa}$ \\
Leak rate & $<0.01 \mathrm{sccm}$ \\
Switching Time & $<500 \mathrm{~ms}$ \\
Valve clearance & $>30 \mu \mathrm{m}$ \\
Size & $<0.25 \mathrm{~cm}^{3}$ \\
\hline
\end{tabular}

Numerous valve designs have been explored both in industry and academia [1,2]. Electrostatic actuators are very low power and have fast response times but are sensitive to particulates and have low clearance and low open flow. Electromagnetic valves can achieve good performance, but the forces scale unfavorably for devices with small volume. Piezoelectric actuators can exhibit large actuation forces and fast response times, but have low throw and require large voltages. Sol-gel based valves have achieved large volumetric displacement but usually require liquid for actuation. Thermopneumatic valves are robust and have high force and large throw but require continuous power to remain actuated.

Attempts have been made to combine multiple actuation principles in hybrid or bistable designs with the goal of alleviating the drawbacks of a single actuation mechanism. In 1993, Bosch et al. developed a hybrid electromagnetic and electrostatic valve for low pressure applications that consumed $50 \mathrm{~mW}$ of power when actuated, had a $0.4 \mathrm{~ms}$ response time and a leak rate of $0.01 \mathrm{sccm}$ [3]. In 1996 Wagner et al. investigated a valve based on two pneumatically-coupled membranes and electrostatic actuation [4]. When one electrode was pulled down electrostatically, the other was forced upward pneumatically. In 2000, Capanu et al. presented an electromagnetically-actuated valve with mechanical bistability, an open flow of $330 \mathrm{sccm}$ at $6.2 \mathrm{kPa}$, and a response time of $38 \mathrm{~ms}$, and requiring $380 \mathrm{~mW}$ to transition between states [5]. In 2004, Frank and Pisano reported a mechanically bistable valve with electrolysis actuation that required less than $1 \mathrm{~mW}$ to transition between states and had a leak rate of $0.002 \mathrm{sccm}$ at $117 \mathrm{kPa}$, but required $10 \mathrm{~s}$ to close and had a low open flow rate [6]. In 2008, Shaikh et al. demonstrated a latching microvalve employing a low melting point metal alloy and pneumatic actuation [7]. The integrated heater enabled heating and cooling of the alloy in about $130 \mathrm{~ms}$ and complete closure to occur in about $400 \mathrm{~ms}$. In general, each of these valves has advantages and disadvantages. A comparison of the performance of a representative subset of these valves is shown in Table 2.

This paper reports a valve based on combined thermopneumatic and electrostatic actuators. Using this hybrid actuation scheme, the high force and large throw characteristics of thermopneumatic actuators are preserved, while the electrostatic hold reduces the energy requirement of the device. 
It is also shown that this combination can significantly improve the response time compared to a stand-alone thermopneumatic actuator. This work builds on previous work at Michigan on electrostatic actuators [11] and phase-change actuation [12]. Other thermopneumatic microvalves have been developed in the past. In 1997, Henning et al. presented a thermopneumatic microvalve capable of closing in $1 \mathrm{~s}$ at $450 \mathrm{~mW}$ [13]. In 2003, Rich and Wise presented a thermopneumatic microvalve capable of closing in $1.5 \mathrm{~s}$ at $350 \mathrm{~mW}$ and capable of maintaining closure at $30 \mathrm{~mW}$ of power [10]. The current device contains a heater with improved thermal isolation compared to previous devices and integrates an electrostatic actuator into the device to reduce the required hold power and increase speed. In addition, the current valve is an improved version of a device previously presented by the authors [14]. The current device has a more efficient heater design, a faster switching speed, a larger flow conductance, an improved latch design, and a lower leak rate than the prior device. Table 3 describes these improvements in more detail. In addition, this manuscript presents a complete analytical model of the device and provides guidelines for design optimization.

Table 2. Comparison of a representative subset of previous valve technologies. The data emphasizes the difficulty in achieving a large force and throw (large open flow and small leak conductance) valve with low power requirement and fast response time. Flows have been converted to conductances for easier comparison. N/A signifies that the data was not available in the paper. The best performance in each column is highlighted with bold text.

\begin{tabular}{|c|c|c|c|c|c|c|}
\hline & Source & $\begin{array}{c}\text { Open Flow } \\
\text { Conductance } \\
\left(\mathrm{cm}^{3} \mathbf{s}^{-1} \mathbf{P a}^{-1}\right)\end{array}$ & $\begin{array}{c}\text { Steady } \\
\text { State Power } \\
(\mathbf{m W})\end{array}$ & $\begin{array}{c}\text { Response } \\
\text { Time } \\
\text { (ms) }\end{array}$ & $\begin{array}{c}\text { Leak } \\
\text { Conductance } \\
\left(\mathrm{cm}^{3} \mathbf{s}^{-1} \mathbf{P a}^{-1}\right)\end{array}$ & Type \\
\hline \multirow{3}{*}{ 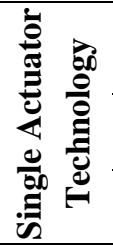 } & Yang [8] & $4.2 \times 10^{-7}$ & 4 & 10 & $3.0 \times 10^{-13}$ & Piezoelectric \\
\hline & Sihler [9] & $2.0 \times 10^{-6}$ & $\mathbf{0}$ & N/A & $6.4 \times 10^{-11}$ & Electrostatic \\
\hline & Rich [10] & $3.3 \times 10^{-5}$ & 30 & 1,000 & $3.1 \times 10^{-10}$ & Thermopneumatic \\
\hline \multirow{4}{*}{ 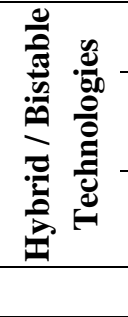 } & Bosch [3] & $2.5 \times 10^{-6}$ & 50 & 0.4 & $1.7 \times 10^{-8}$ & Electromagnetic; electrostatic \\
\hline & Capanu [5] & $8.9 \times 10^{-4}$ & $\mathbf{0}$ & 38 & N/A & $\begin{array}{l}\text { Electromagnetic; mechanically } \\
\text { bistable }\end{array}$ \\
\hline & Frank [6] & $9.7 \times 10^{-7}$ & $\mathbf{0}$ & 10,000 & $3.2 \times 10^{-10}$ & Electrolysis; mechanically bistable \\
\hline & Current & $2.2 \times 10^{-4}$ & 90 & 430 & $3.2 \times 10^{-10}$ & Thermopneumatic \& electrostatic \\
\hline
\end{tabular}

Table 3. Comparison to our previous work [14].

\begin{tabular}{lll}
\hline Category & Previous Design & Current Design \\
\hline Heater Design & $\begin{array}{l}\text { Diamond grid structure; } 10 \mu \mathrm{m} \text { elevation; } \\
\text { Additional support posts decrease } \\
\text { thermal isolation. }\end{array}$ & $\begin{array}{l}\text { Ladder grid structure; } 50 \mu \mathrm{m} \\
\text { elevation; No additional } \\
\text { support posts. }\end{array}$ \\
\hline Switching Speed $(\mathrm{ms})$ & 1000 & 430 \\
\hline $\begin{array}{l}\text { Open Flow Conductance } \\
\left(\mathrm{cm}^{3} \mathrm{~s}^{-1} \mathrm{~Pa}^{-1}\right)\end{array}$ & $3.2 \times 10^{-6}$ & $2.2 \times 10^{-4}$ \\
\hline Latch Design & $\begin{array}{l}\text { Parylene insulator; Can withstand } \\
\text { voltages up to 40 V. }\end{array}$ & $\begin{array}{l}\text { Silicon oxynitride insulator; Can } \\
\text { withstand voltages up to 140 V. }\end{array}$ \\
\hline Measured Leak Rate $(\mathrm{sccm})$ & 0.02 & 0.001 \\
\hline
\end{tabular}


Figure 1. Cross-sectional drawing of the hybrid microvalve structure. Fluid flows from the inlet to the outlet when open. Valve closure occurs when the valve plate is in contact with the valve seat, stopping flow. To close the valve, the heater energizes the working fluid, increasing pressure in the thermopneumatic cavity and driving the valve plate upward. The electrostatic latch senses the valve plate position through its capacitance. Once closed, the latch can be used to reduce or eliminated power to the heater. The electrical feedthrough serves to transfer electrical connections from the top to the bottom wafer.

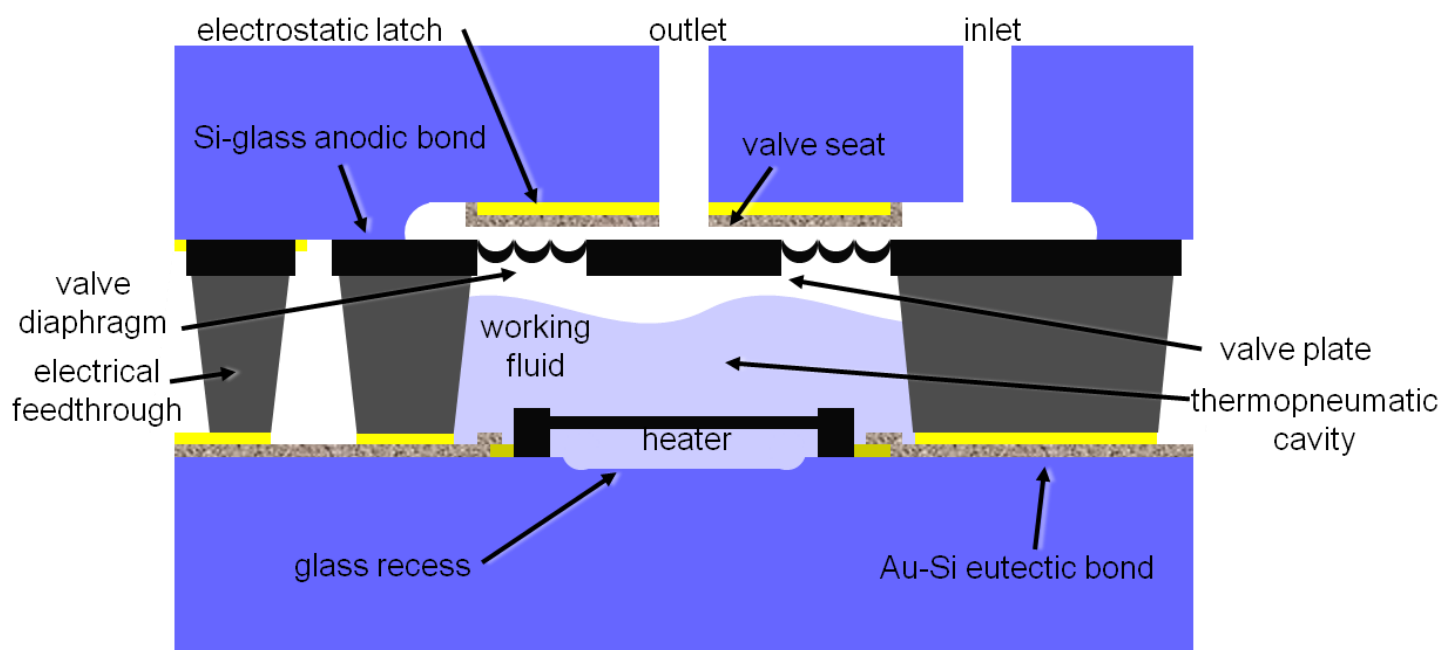

The overall structure of the normally-open valve is shown in Figure 1. To close the device, an elevated heater grid energizes a working fluid, raising the pressure in the cavity and deflecting the corrugated diaphragm and valve plate. The heater is suspended in order to increase its heating efficiency and the corrugations serve to decrease the spring constant of the diaphragm, permitting valve travel greater than $30 \mu \mathrm{m}$. The capacitive pressure sensor reads out the cavity pressure and valve seat position, providing feedback to determine when to enable the electrostatic actuator. Once latched, the power to the heater can be reduced or eliminated; thus, ideally, the valve only requires power to transition from open to closed and consumes no static power. In addition, hybrid actuation may help alleviate the particulate problem common to electrostatic actuators because, in this case, the electrostatic voltage is only applied after the device is closed and thus charged particles are less likely to be trapped on the sealing surface.

\section{Design, Construction and Experimental}

\subsection{Theory and Design}

For a hybrid thermopneumatic and electrostatic valve, there are several important performance metrics, including the speed, power, clearance, leak rate and open flow rate. Tradeoffs exist among each of them as detailed in the next sections.

\subsubsection{Diaphragm Deflection Theory}

The diaphragm and valve plate are the moving components of the valve, and their position determines the flow rate through the valve and the valve state (open or closed). For the current device, an etched 
back p++ silicon layer was chosen as the diaphragm structural material due to its robustness and proven performance [10]. The diaphragm was corrugated in order to reduce its spring constant. The equation governing the deflection of bossed corrugated diaphragms was estimated in $[15,16]$ and an approximation is given in Equation (1).

$$
\frac{P R^{4}}{E^{\prime} h^{4}}=A_{P} N_{P} \frac{y}{h}+B_{P} N_{P} \frac{y^{3}}{h^{3}}
$$

In this equation, $P$ is the pressure, $R$ is the diaphragm radius, $y$ is the deflection of the valve plate and $\mathrm{h}$ is the thickness of the diaphragm. $E^{\prime}, A_{P}, B_{P}$, and $N_{P}$ are defined in the following equations.

$$
\begin{gathered}
E^{\prime}=\frac{E}{1-v^{2}} \\
A_{P}=\frac{2(q+3)(q+1)}{3\left(1-\frac{v^{2}}{q^{2}}\right)} \\
B_{P}=\frac{165(q+1)^{3}(q+3)}{q^{2}(q+4)(q+11)(2 q+1)(3 q+5)} \\
\frac{1}{N_{P}}=\left(1-r^{4}\right)\left(1-\frac{8 q r^{4}\left(1-r^{q-1}\right)\left(1-r^{q-3}\right.}{(q-1)(q-3)\left(1-r^{2 q}\right)}\right)
\end{gathered}
$$

$E$ and $v$ are the Young's Modulus and Poisson's Ratio of the diaphragm material and $r$ is the ratio of boss radius to diaphragm radius. $q$, the corrugation quality factor and for shallow, sinusoidal profiles is given by Equation (6), where $\mathrm{H}$ is the corrugation depth.

$$
q^{2}=1+1.5 \frac{H^{2}}{h^{2}}
$$

In these equations, the initial stress of the diaphragm is ignored, but can be added as a term on the right side of Equation (1) [17]. When deflection versus pressure is plotted using Equation (1), it is immediately apparent that there is an initial period where a small increase in differential pressure yields a large deflection. For valves with low flow-rate requirements, it would be advantageous to operate in this regime. After the initial period, further increases in deflection require larger increases in differential pressure.

Equation (1) shows the large impact that the diaphragm thickness (h) has on the diaphragm's characteristics. By decreasing the thickness from 4.2 to $3 \mu \mathrm{m}$, the required pressure to achieve a $38 \mu \mathrm{m}$ deflection is reduced from $209 \mathrm{kPa}$ to $103 \mathrm{kPa}$. Thus, the choice of diaphragm thickness impacts the rest of the valve design. In the end, the equations above and previous experience were utilized to choose an outer radius of $750 \mu \mathrm{m}$, boss radius of $475 \mu \mathrm{m}$, and $2 \mu \mathrm{m}$ corrugation depth. After fabrication was completed (see Section 2.2), diaphragm thickness was measured at $4.2 \mu \mathrm{m}$.

\subsubsection{Thermopneumatic Theory}

At the heart of the microvalve is the thermopneumatic actuator. Using previous experimental data $[10,14]$, a first order thermal model of the actuation cavity can be derived as shown in Figure 2. 
$\mathrm{R}_{\mathrm{L}}$ and $\mathrm{C}_{\mathrm{L}}$ are the thermal resistance and capacitance of the working fluid and $\mathrm{R}_{\mathrm{S}}$ and $\mathrm{C}_{\mathrm{S}}$ are the thermal resistance and capacitance of the silicon and glass substrates. This model makes several assumptions, all of which have been shown valid $[10,14]$. First, the model assumes efficient heating: that the heat lost through the support posts of the heater is negligible and that all of the energy is generated in the elevated heater grid. The former can be accomplished by minimizing the cross-sectional area of the heater and the latter through the use of low-resistance electrical interconnects. Second, the model assumes that conduction is the main source for heat loss in the system. Thus, the effects of convection and radiation have been ignored.

Figure 2. First order thermal circuit for thermopneumatic actuator (a) and simulated transient response for the standalone, energized thermopneumatic actuator with a close-up of the first $400 \mathrm{~ms}(\mathbf{b})$. I represents the power applied to the heater. $\mathrm{R}_{\mathrm{L}}$ and $\mathrm{C}_{\mathrm{L}}$ are the thermal resistance and capacitance from the heater to the surrounding valve body. $\mathrm{C}_{\mathrm{L}}$ is dominated by the capacity of the working fluid. $\mathrm{R}_{\mathrm{L}}$ is dominated by the resistance of the working fluid (liquid) under the heater grid. $\mathrm{C}_{S}$ and $\mathrm{R}_{\mathrm{S}}$ are the thermal resistance and capacitance of the valve substrate/body surrounding the thermopneumatic chamber. In the simulation, the input power of $250 \mathrm{~mW}$ was applied at $0 \mathrm{~s}$ and removed at $20 \mathrm{~s}$.

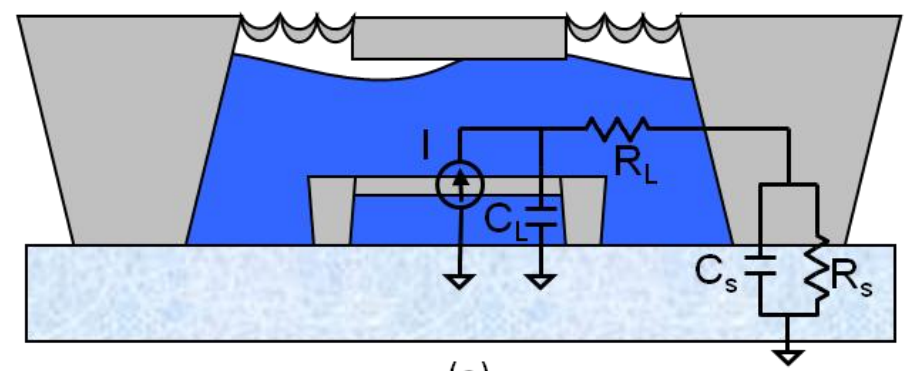

(a)

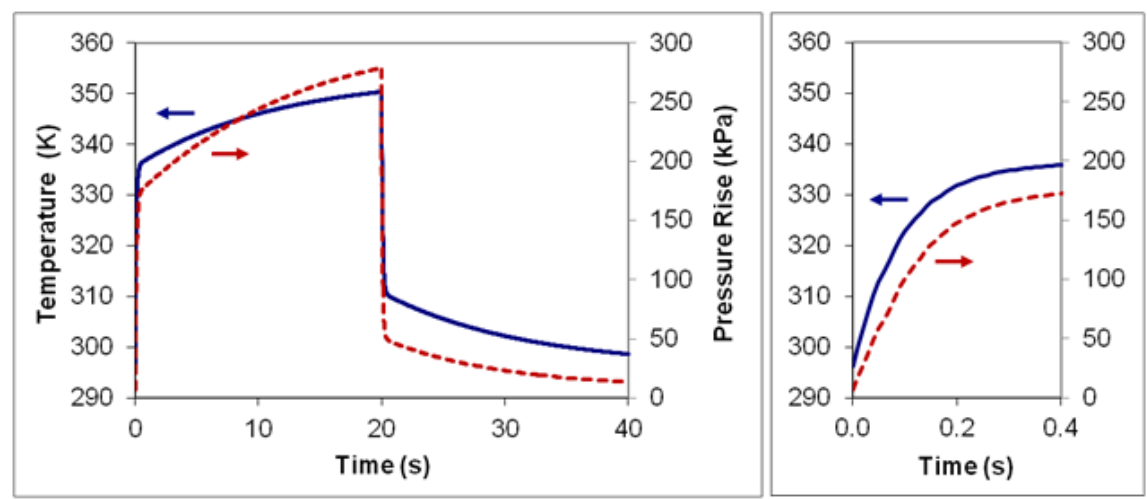

(b)

The thermal resistances and capacitances in the circuit were calculated using Equations (7) and (8). $L, A$, and $V$ are the length, area, and volume of the material and are given in the direction of heat transfer. $\sigma$ is the thermal conductivity of the material, $c$ is its heat capacity, and $\rho$ is its density.

$$
\begin{gathered}
R_{T H}=\frac{L}{A \times \sigma} \\
C_{T H}=c \times V \times \rho
\end{gathered}
$$


The calculations result in $\mathrm{R}_{\mathrm{L}}=158 \times 10^{-3} \mathrm{~K} / \mathrm{mW}, \mathrm{C}_{\mathrm{L}}=5.7 \times 10^{-4} \mathrm{~J} / \mathrm{K}, \mathrm{R}_{\mathrm{S}}=71 \times 10^{-3} \mathrm{~K} / \mathrm{mW}$, and $\mathrm{C}_{\mathrm{S}}=0.16 \mathrm{~J} / \mathrm{K} . \mathrm{R}_{\mathrm{L}}$, the thermal resistance from the heater grid to the valve body, was calculated assuming that the working fluid fills $20 \%$ of the actuation cavity; it is dominated by losses through the working fluid directly below the heater grid. $\mathrm{R}_{\mathrm{S}}$ includes the resistance of the substrate in addition to the resistance of the PCB board that the device was mounted on for testing.

The circuit in Figure 2 was simulated in HSpice assuming a $50 \mu \mathrm{m}$ recess below the heater and an input power of $250 \mathrm{~mW}$. The power was applied at $0 \mathrm{~s}$ and removed at $20 \mathrm{~s}$. The simulation results are shown in Figure 2 and display two distinct regimes of heating. In the first, the working fluid temperature increases rapidly with little required energy. In the second, much more energy is consumed as the rest of the valve slowly heats up. Thus, to fully maximize the performance and minimize the energy requirements of the valve, the device should be designed such that the temperature rise in the first heating regime is sufficient to close the valve. Ideally, the valve will then be latched (after the first heating regime), and operation in the second regime will be completely avoided, saving energy and improving the closing speed. In addition, if the second heating regime is avoided, less thermal energy will need to be dissipated from the device in order to cool down the fluid and open the valve again. Thus, the hybrid actuator has the potential to greatly increase the speed of the device during both transitions (open-to-closed and closed-to-open). The capacitance of the electrostatic latch is used to monitor the valve seat position to determine the state of the valve and when to latch in order to minimize energy consumption. As shown in Figure 2, the simple thermal model predicts a temperature rise of $39 \mathrm{~K}$ in $400 \mathrm{~ms}$ while consuming $100 \mathrm{~mJ}$ of energy for a $50 \mu \mathrm{m}$ recess under the heater. If the recess under the heater is increased to $100 \mu \mathrm{m}$, the same temperature rise can be achieved in $230 \mathrm{~ms}$ according to the model.

This valve uses a rectangular design for the heater grid, in contrast to the diamond-shaped grids in [12] and [14], which were used to promote wetting by the fluid and heat transfer to the fluid. The diamond-shaped grids were designed for low fill fractions of the working fluid. In this work, larger fill fractions are assumed and a rectangular grid was chosen to increase the resistance and efficiency of the heater, increase the heat transfer area to the fluid, and increase the structural integrity of the heater. In [12], additional anchors were used throughout the grid to improve its mechanical stability; however, this reduced its thermal isolation. The current grid does not use additional anchors.

Utilizing the temperature of the cavity as predicted using the model above, the pressure generated by the thermopneumatic actuator can be calculated using the Clausius-Clapeyron relation [10], which provides the pressure of a working fluid in a closed cavity as a function of temperature.

$$
p_{g}=p_{g, o} \times \exp \left\{-\frac{M \Delta h_{\mathrm{lg}}}{R_{g}}\left(\frac{1}{T_{\mathrm{lg}}}-\frac{1}{T_{\mathrm{lg}, o}}\right)\right\}
$$

In Equation (9), $p_{g}$ and $T_{\mathrm{lg}}$ are the pressure and temperature (in $\mathrm{K}$ ) of the working fluid and gas in the cavity, $p_{g, o}$ and $T_{\mathrm{gg}, o}$ are the initial pressure and temperature of the working fluid and gas in the cavity, $M$ is its molecular mass of the working fluid, $\Delta h_{\mathrm{lg}}$ is the heat of vaporization, and $R_{g}$ is the universal gas constant. The pressure of the residual air in the cavity must also be taken into account and can be calculated using the ideal gas law and the law of partial pressures. In general, the lower the boiling point of the working fluid, the larger the pressure it generates for a given temperature. For the 
current work, pentane was chosen as the working fluid for its low boiling point $\left(36^{\circ} \mathrm{C}\right.$ at $\left.101.325 \mathrm{kPa}\right)$, ease of handling, and availability. The simple thermal model and Equation (9) were used to estimate the pressure response of the system versus time as shown in Figure 2, which predicts a pressure rise of $173 \mathrm{kPa}$ in $400 \mathrm{~ms}$ and $280 \mathrm{kPa}$ in $20 \mathrm{~s}$.

\subsubsection{Flow Theory}

Because the valve is being developed as part of a $\mu \mathrm{GC}$ system, it is critical that it have a low pressure drop in order to reduce its impact on the rest of the system. That is, if the valve has a large fluidic resistance (small fluidic conductance) when open, it will reduce the flow rate during all stages of operation and negatively impact system performance. Thus, it is advantageous to maximize the flow conductance (flow rate for a given pressure) of the valve. The flow rate can be calculated from standard fluid flow theory as in Equation (10).

$$
Q=\frac{P_{D I F F}}{R_{F L U I D}}=\frac{P_{D I F F}}{\left(\frac{12 \eta L}{W h^{3}}\right)}
$$

In this equation, $P_{D I F F}$ is the differential pressure across the flow channel, $R_{F L U I D}$ is the fluidic resistance of the channel, $\eta$ is the viscosity of the fluid, $L$ is the length of the channel, $W$ is the channel width and $h$ is the height of the channel. This equation is valid for two parallel plates and incompressible flow. In the current device, a channel width of $2.3 \mathrm{~mm}$ was chosen to accommodate the width of the valve membrane $(1.5 \mathrm{~mm}$ ) and a length of $3 \mathrm{~mm}$ was chosen for ease of testing. A channel height (also the required valve plate travel distance) of $38 \mu \mathrm{m}$ was chosen as a tradeoff between fabrication considerations, the pressure required to close the valve, and the desire to maximize the flow rate. Assuming a viscosity of $1.8 \times 10^{-5} \mathrm{Ns} / \mathrm{m}^{2}$ for air, the model predicts a flow rate of $8 \mathrm{sccm}$ for a differential pressure of $670 \mathrm{~Pa}$.

\subsubsection{Position Sensor Theory}

The position sensor in the valve is capacitive and is based on the variation of capacitance with distance. For the current valve, the total capacitance is determined by three separate capacitances: the capacitance of the air between the valve plates, the capacitance of the insulating dielectric on the top electrode, and parasitic capacitance; only the capacitance of the air changes (Figure 1). The total capacitance of the pressure sensor can be written as the combination of the three capacitances.

$$
C_{T}=\left(\frac{1}{C_{\text {AIR }}}+\frac{1}{C_{I N S}}\right)^{-1}+C_{P}
$$

$C_{T}$ is the total capacitance, $C_{A I R}$ and $C_{I N S}$ are the capacitance of the air and insulator and are calculated using the equation for a parallel plate capacitor $(\mathrm{C}=\varepsilon \mathrm{A} / \mathrm{d})$, and $C_{P}$ is the parasitic capacitance. In the capacitance equation, $\varepsilon$ is the permittivity of the dielectric material, $A$ is the area of the electrodes and $d$ is the distance between the electrodes. A capacitor area of $5.2 \times 10^{-7} \mathrm{~m}^{2}$, insulator and air relative permittivities of 3.9 and 1.0, respectively, an insulator thickness of $2.3 \mu \mathrm{m}$, an initial air gap of $38 \mu \mathrm{m}$, and a parasitic capacitance of $2.7 \mathrm{pF}$ were assumed in the calculations. In addition, it 
was assumed that the capacitance reached a maximum and no longer increased when the valve plate was predicted to be fully actuated.

\subsubsection{Electrostatic Latch Theory}

The spring constant of the diaphragm has a large impact on the voltage required to completely latch the valve in the closed position. The force of an electrostatic actuator is given by Equation (12).

$$
F_{E}=\frac{A_{E} V^{2} \varepsilon}{2 t^{2}}
$$

In this equation, $A_{E}$ is the area of the electrostatic actuator, $V$ is the electrostatic voltage, $\varepsilon$ is the permittivity of the dielectric, and $t$ is the dielectric thickness. In order for the valve to completely latch, the electrostatic actuator must generate a force that is equal to or greater than the force required to close the valve. An estimate of this force may be determined by multiplying the pressure of the pneumatic actuator by the effective area of the diaphragm. Once this force is known, Equation (12) may be solved for the required latching voltage. The electrostatic electrode area, relative permittivity of the dielectric, and dielectric thickness were assumed to be $5.2 \times 10^{-7} \mathrm{~m}^{2}, 3.9$ and $2.3 \mu \mathrm{m}$, respectively. For a diaphragm thickness of $4.2 \mu \mathrm{m}$, a pressure of $209 \mathrm{kPa}$ is required for a valve plate deflection of $38 \mu \mathrm{m}$. Rearranging Equation (12) and substituting in the numbers above results in an estimated minimum latching voltage of $250 \mathrm{~V}$. This relatively high could be reduced significantly by decreasing the diaphragm thickness, increasing its size, or increasing the electrode area.

\subsection{Fabrication}

The fabrication of the valve, shown in Figure 3, begins with the formation of a deep boron etch-stop $(\sim 10 \mu \mathrm{m})$ to define the valve body (Figure 3(a)). Next, a shallow isotropic etch is performed to define the diaphragm corrugations and to recess the wafer areas that will not be anodically bonded later (Figure 3(b)). A shallow boron diffusion $(\sim 4 \mu \mathrm{m})$ then defines the valve diaphragm, and $\mathrm{Cr} / \mathrm{Au}$ metallization is patterned on the front of the wafer to form a substrate electrical contact during the anodic bond (Figure 3(b)). Next, Cr/Au metallization is patterned on the bottom of the wafer (Figure 3(b)). This later will later serve to form a Si/Au eutectic bond with the heater wafer. Separately, a $38 \mu \mathrm{m}$ recess is wet etched using HF in a Pyrex wafer to form the fluidic flow channel and accommodate valve plate movement (Figure 3(c)). Next, a Ti/Pt/Au layer is deposited and patterned to form the top electrode of the electrostatic latch and position sensor; the bottom electrode is the substrate of the silicon wafer (Figure 3(c)). Then, a PECVD oxynitride film is deposited and patterned to insulate the top electrode (Figure 3(c)). This insulator only exists in the recessed area and thus does not affect the anodic bond. Fluidic ports are wet etched in the glass wafer using a $\mathrm{NaOH}$ electrochemical etch, and the two wafers are anodically bonded together (Figure 3(d)). Finally, an ethylene diamine pyrocatechol (EDP) etch is done to release the valve seat and diaphragm and separate individual valve bodies (Figure 3(d)). A released valve body wafer is shown in Figure 4. The EDP etch forms pillars that will later serve as lead transfers for electrical signals between the top and bottom wafer. 
Figure 3. The fabrication process for the microvalve. The valve body (a-d) and heater $(\mathbf{e}-\mathbf{g})$ are formed using a silicon-on-glass process and processed in parallel. A deep boron diffusion is utilized to define the valve body and plate (a) as well as the heater anchors (e). The glass is recessed to form fluid channels (c) and improve heater isolation (f). A metallization step is performed for electrical contact to the valve components $(\mathbf{b}, \mathbf{c}, \mathbf{f})$. An anodic bond seals the valve body to the top glass wafer (d) and the heater to the bottom glass wafer (g) and the undoped silicon is removed in an EDP etch ( $\mathbf{d}$ and $\mathbf{g})$. The valve body wafer and heater wafer are then bonded together using a Au-Si eutectic or epoxy bond (h).

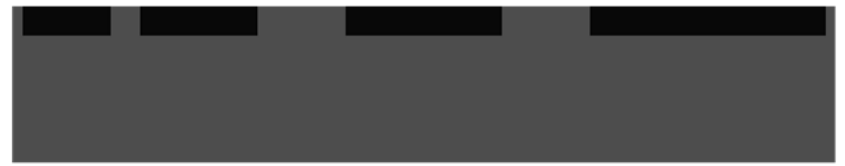

(a)

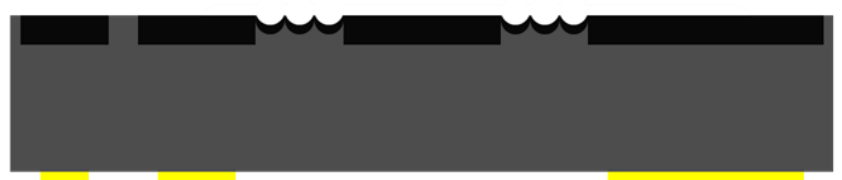

(b)

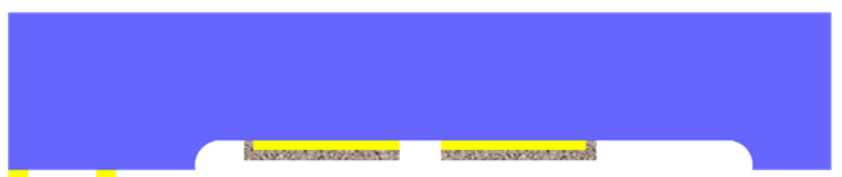

(c)

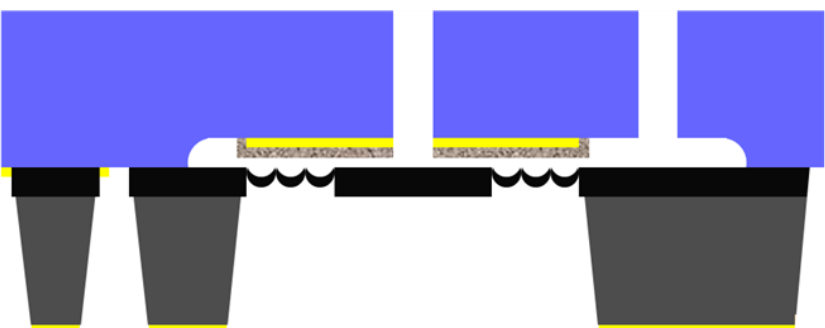

(d)

$\begin{array}{ll}\text { Silicon } & \text { Boron-doped silicon } \\ \text { Gold } & \text { Pyrex }\end{array}$

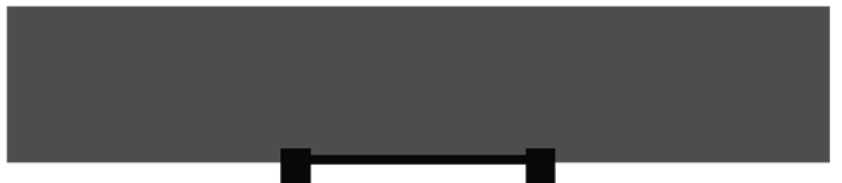

(e)

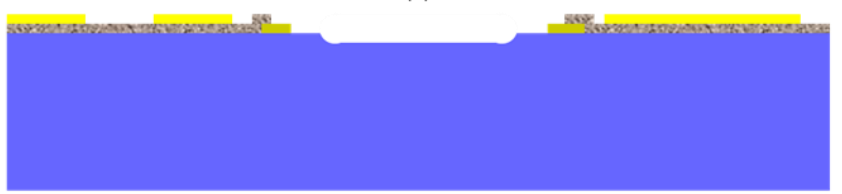

(f)

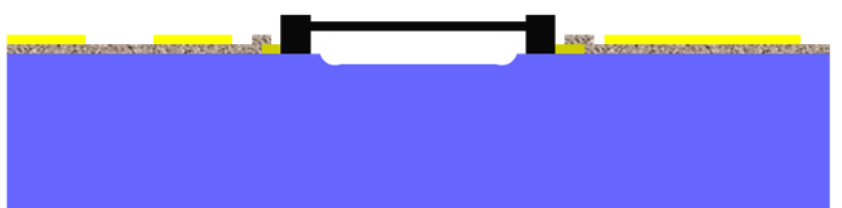

(g)

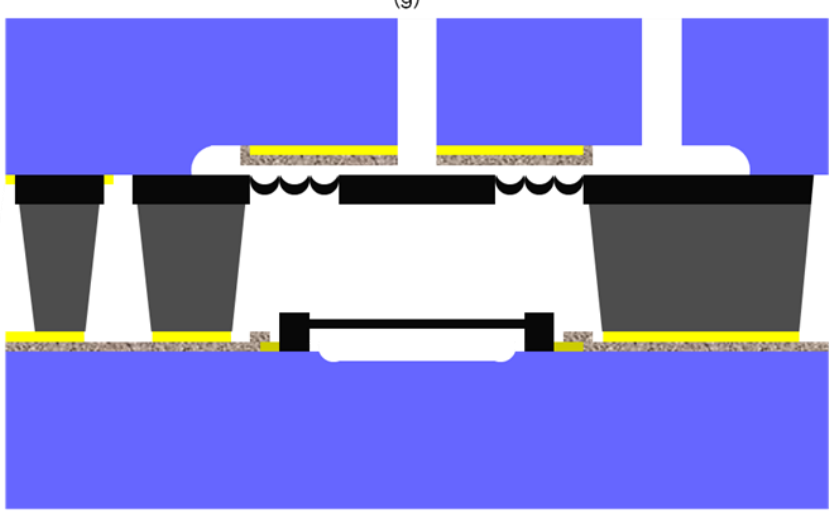

(h)

The elevated heater is formed in an analogous manner to the process described above, and, in fact, the two wafers can be processed in parallel. The fabrication begins with a short isotropic etch (to elevate the heater) on the silicon wafer, following with patterned deep and shallow boron diffusions and contact metallization (Figure 3(e)). On a separate Pyrex wafer, a Ti/Pt/Au metal layer is deposited and patterned to form the electrical leads, a PECVD oxynitride is deposited and patterned to insulated the leads, a Ti/Pt/Au layer is plated to form a bond ring (for the final $\mathrm{Au} / \mathrm{Si}$ eutectic bond [18]), and fluidic ports are etched through the glass wafer (Figure 3(f)). These ports are later used to fill the device with the working fluid. An electrostatic bond is then performed, and an EDP etch is utilized to release the heater (Figure 3(g)). A finished heater is shown in Figure 4 (lower left). Finally, the valve body wafer and the heater wafer are bonded together utilizing a $\mathrm{Si} / \mathrm{Au}$ eutectic bond, and then diced to separate the individual die (Figure 3(h)). After fabrication, the die are injected with the working fluid (pentane) and sealed with epoxy. Capillary tubing was then epoxied into the fluidic ports of the valve for testing. 
In some of the devices, capillary tubing was attached to the actuation chamber using epoxy for perform pneumatic testing.

Figure 4. Pictures of the top (upper left) and bottom (upper right) of the finished valve body wafer, a released, suspended heater grid (bottom left) and completed device on a penny (bottom right). The fluidic input and output are visible in the top left image. The valve diaphragm, plate, and actuation are visible in the upper right picture. The improved isolation (due to the glass recess) of the heater is visible in the bottom left.
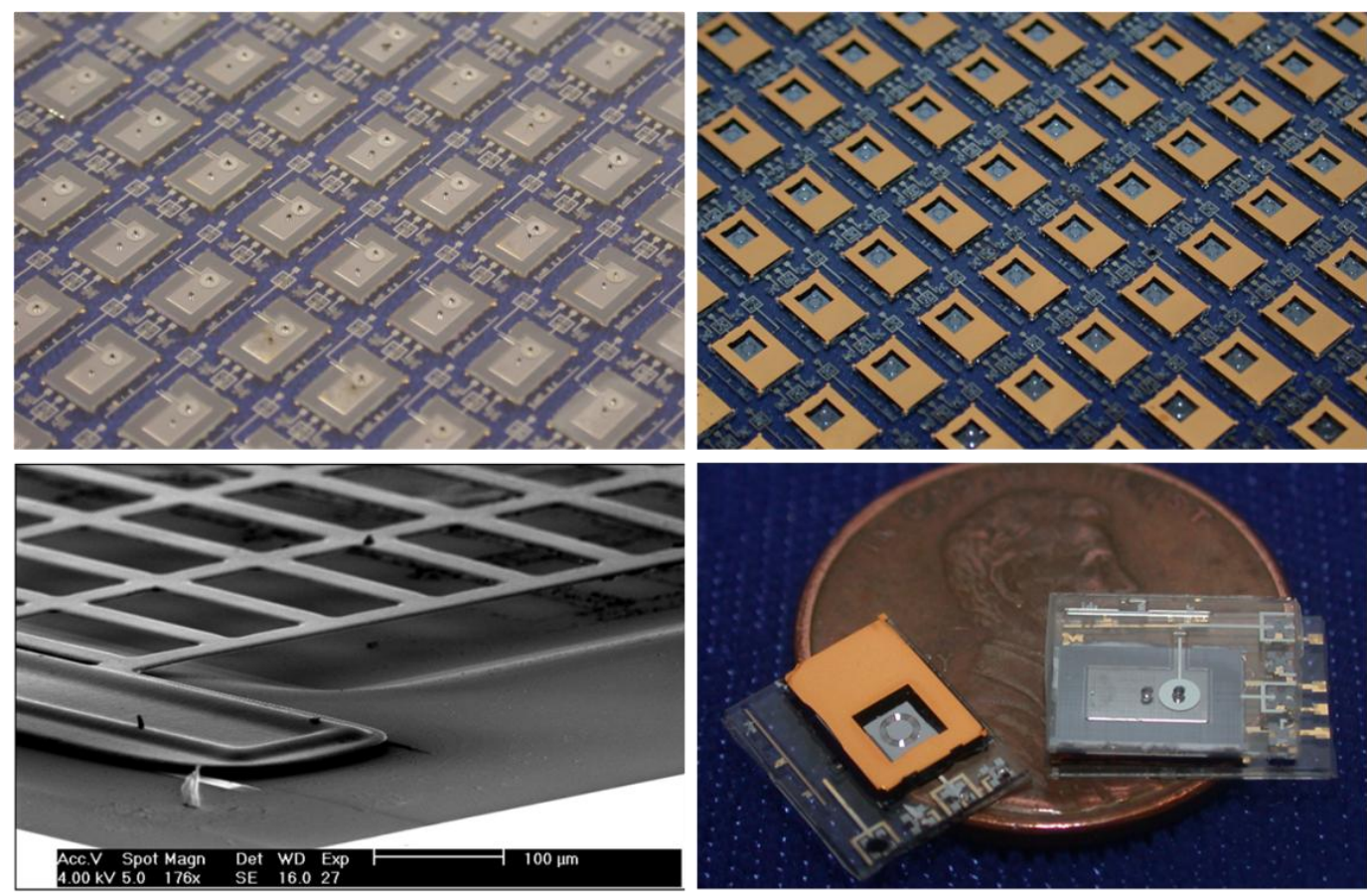

\subsection{Experimental Setup}

Inspection and measurements were performed using both standard and scanning electron microscopy (SEM). Resistance values were measured using a probe station and Keithley 2000 Digital Mutlimeter (DMM) in a four point probe configuration. Capacitance values were measured using a HP 4284A LCR meter. Unless otherwise stated, pressures were fixed with a standard $60 \mathrm{psi}(414 \mathrm{kPa}$ ) pressure regulator and verified using two MKS 740 pressure sensors at the input and output of the device under test. Flow rates were measured using an MKS $17010 \mathrm{sccm}$ flow meter. Nitrogen was used as the test gas in all cases. Valve leak rates $(<0.01 \mathrm{sccm})$ were determined by measuring the change in pressure over time for a small fixed volume at the outlet of the closed valve as described in detail in [10]. The pressure/flow characteristics of the test setup were measured before inserting the valve for testing. With this method, the values of the test setup could be subtracted from those of the valve and test setup to determine the values for the valve alone. Transient measurements were captured via a GPIB interface and LabView ${ }^{\circledR}$.

\subsubsection{Open Flow Characterization}

Pressure was fixed using a DH Instrument PPC2 programmable pressure controller. Pressure and flow were measured using two pressure sensors and a flow sensor, described above. 


\subsubsection{Position Sensor Characterization}

The thermopneumatic actuation chamber was connected to a DH Instrument PPC2 programmable pressure controller. The valve flow input and output were open to ambient. The capacitance of the sensor was measured using an LCR meter as pressure was varied using the PPC2 controller.

\subsubsection{Pneumatic Switching Characterization}

The thermopneumatic actuation chamber was connected to the PPC2 pressure controller and flow rate through the valve was measured as a function of actuation pressure, yielding the actuation pressure required to close the valve at various initial flow rates.

Pneumatic testing was also utilized to determine the base switching capabilities of the valve and the time constant of the test setup. A custom pressure controller containing a pressure regulator and high speed solenoid valve was utilized to rapidly switch $(<50 \mathrm{~ms})$ between ambient and a set pressure. This custom pressure controller was connected to the thermopneumatic actuation chamber. Flow through the valve was set to a start value and flow and pressure were measured as a function of time.

Due to the nature of the test setup, the pressure across the flow path in the valve varied as a function of the valve state. That is, when the valve was open, the fluidic resistance of the valve was small compared to that of the tubing in the test setup. This caused the pressure difference across the valve to be small when open. However, when the valve was closed, the fluidic resistance of the valve was much greater than that of the test setup causing the differential pressure across the flow path of the valve to be large.

\subsubsection{Thermopneumatic Characterization}

The thermopneumatic actuator was tested after filling devices with pentane and sealing them with Loctite $^{\circledR} 1 \mathrm{C}^{\text {TM }} \mathrm{Hysol}^{\circledR}$ epoxy. After drying, the device was inserted into the test setup and an initial flow through the device was fixed. Power was then applied to the heater in the actuation chamber using a Keithley 2400 Source Measure Unit (SMU). Flow and pressure (across the input and output) were measured as a function of time.

\subsubsection{Electrostatic Latch Testing}

First, the open flow rate of the valve was set to $0.06 \mathrm{sccm}$ and then the valve was pneumatically actuated with a pressure of $270 \mathrm{kPa}$. This pressure was chosen as it was sufficient to close the valve with a leak rate less than $5 \times 10^{-3} \mathrm{sccm}$ in previous tests. Then, a voltage was applied to the electrostatic latch with a HP 6209B power supply and the valve leak rate was measured as described above.

A second test was performed to determine if the electrostatic latch could be utilized to reduce the required pressure supplied by the pneumatic or thermopneumatic actuator, thereby reducing energy requirements. For this test, the valve was pneumatically actuated with a pressure of $270 \mathrm{kPa}$ and a valve "initial leak rate" was measured. The electrostatic latch was then activated at $140 \mathrm{~V}$ and then the pneumatic pressure was then decreased until the leak rate through the valve increased above the initial leak rate. 


\section{Results and Discussion}

\subsection{Microscopy and Resistance Results}

From measurements performed during Scanning Electron Microscopy (SEM), the deep boron diffusion layer was $12 \mu \mathrm{m}$ thick, the shallow boron layer that forms the diaphragm was $4.2 \mu \mathrm{m}$ thick, and the initial valve gap distance (or travel distance) was $38 \mu \mathrm{m}$.

From resistance measurements, the suspended, p++ heater resistance was found to be between 7 and $10 \Omega$, depending on the device. This low resistance is due to the high conductivity of $\mathrm{p}++$ silicon and the relatively large cross-section of each heater beam $(32 \times 4.2 \mu \mathrm{m})$. This equates to a resistance of about $56 \Omega$ for each of the $8,1.7 \mathrm{~mm}$-long beams in the heater. Next, the resistance of the gold interconnects was measured to be about $13 \Omega$ giving a total heater and lead resistance of about $20 \Omega$. This parasitic resistance is undesirable in that heat generated in the high resistance leads is not applied directly to the working fluid and instead serves to increase the temperature of the valve substrate. The interconnects were inspected closely under an optical microscope and SEM to determine the cause. Near the point where the gold leads meet the p++ silicon heater, the gold is discolored and has a higher resistance than the rest of the lead. It is believed that during anodic bonding, silicon diffuses into the gold leads forming a eutectic and increasing its resistance.

\subsection{Open Flow Results}

The measured and theoretical open flow rate of the valve at various pressures is shown in Figure 5(a). The valve had an open flow rate of $8 \mathrm{sccm}$ at $600 \mathrm{~Pa}$ corresponding to a fluidic conductance of $2.2 \times 10^{-4} \mathrm{~cm}^{3} \mathrm{~s}^{-1} \mathrm{~Pa}^{-1}$.

Figure 5. Measured results for the microvalve; (a) Measured and theoretical open flow rate. (b) Measured and theoretical response of the position sensor as a function of pressure applied to the actuation cavity. The theoretical response was calculated using Equations (1) and (11) to determine deflection and capacitance. The calculation assumes that capacitance stops increasing once the valve plate makes contact with the valve seat. (c) Measured results for the pneumatic switching of $2 \mathrm{sccm}$. The flow changes more slowly than the sensor capacitance due to the fluidic time constant of the test setup. (d) Measured thermopneumatic transient response with $90 \mathrm{~mW}$ applied to the heater. Although slow, the valve closes at this power level. Flow sensor resolution in the plot is limited to $0.01 \mathrm{sccm}$. (e) Measured thermopneumatic transient response with $250 \mathrm{~mW}$ applied to the heater and (f) a close-up of the transition.

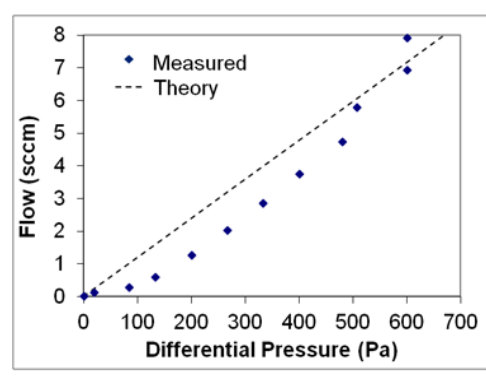

(a)

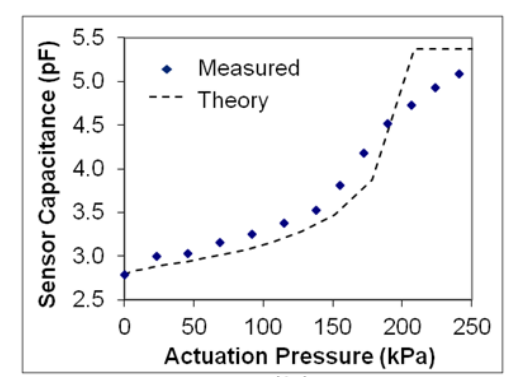

(b)

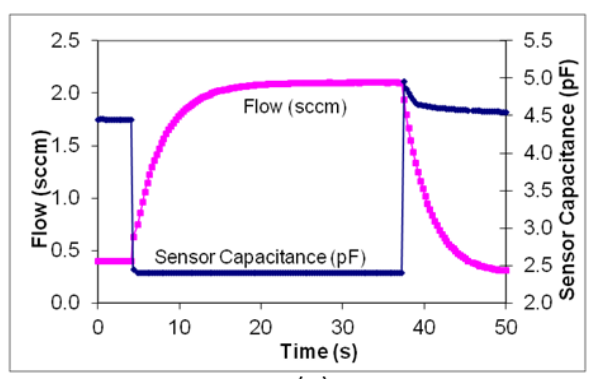

(c) 
Figure 5. Cont.

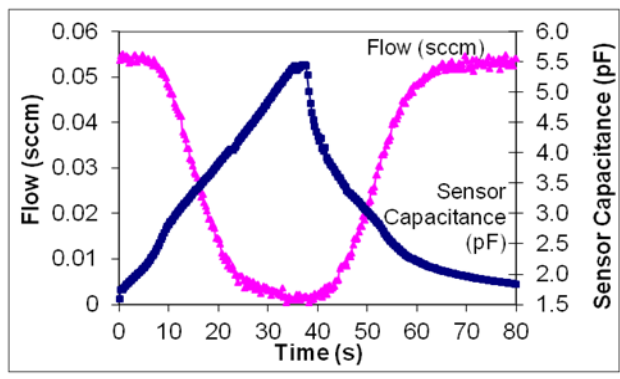

(d)

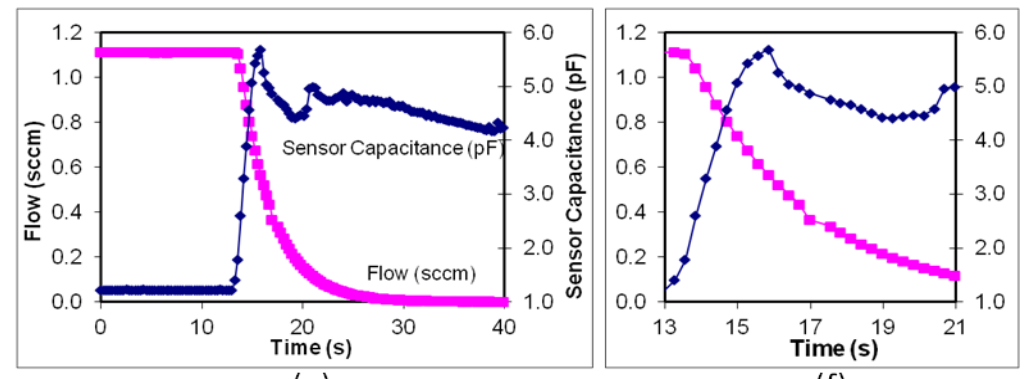

(e)

(f)

\subsection{Position Sensor Results}

The capacitance of the sensor increased as the pneumatic pressure applied to the actuation cavity increased as shown in Figure 5(b). Overall, the capacitive position sensor had a sensitivity of $9.8 \mathrm{fF} / \mathrm{kPa}$ over its operating range.

\subsection{Pneumatic Switching Results}

In pneumatic testing, the valve began to close (flow rate through the valve decreased) at actuation pressures above $170 \mathrm{kPa}$. The actual closing pressure depends on the open flow rate and the required leak rate for a given application. Higher closing pressures are required for larger open flow rates (larger differential pressures) and smaller leak rates.

Results from pneumatic switching tests are shown in Figure 5(b) for an initial open flow rate of $2 \mathrm{sccm}$ and a pneumatic actuation pressure of $200 \mathrm{kPa}$. Due to the nature of the test setup, the pressure across the valve flow path increases from $280 \mathrm{~Pa}$ when open to $40 \mathrm{kPa}$ when closed (see Section 2.3.3). Although the leak rate of the valve was $0.3 \mathrm{sccm}$ in this test, the leak rate can approach $0.001 \mathrm{sccm}$ for a larger actuation pressure. The time constant of the test setup can also be determined from Figure 5(b). When the pneumatic pressure is switched closing the valve, the capacitance increases very rapidly ( $<250 \mathrm{~ms}$ ) from $2.5 \mathrm{pF}$ to $5 \mathrm{pF}$. The much slower switching time (90\%-10\% of $6.7 \mathrm{~s}$ ) of the flow reflects the fluidic time constant of the test setup and not the valve itself.

\subsection{Thermopneumatic Switching Results}

After filling the devices with pentane, power was applied to the heater in the actuator cavity and the flow and capacitance of the position sensor were measured. At $90 \mathrm{~mW}$ applied to the heater $(260 \mathrm{~mW}$ total applied to the elevated p++ silicon heater and gold leads) and an open flow rate of $0.054 \mathrm{sccm}$, the combined valve and test setup have a flow rate switching time (90\%-10\%) of $13.6 \mathrm{~s}$. Subtracting out the time constant of the test setup, this gives a switching time of $6.9 \mathrm{~s}$. Due to the nature of the test setup, when the valve is open, the differential pressure across it is $70 \mathrm{~Pa}$. When the valve is closed, the pressure across it is $1.3 \mathrm{kPa}$. The leak rate for the closed valve is $1.3 \times 10^{-3} \mathrm{sccm}$.

At an open flow rate of $6.74 \mathrm{sccm}$, when $200 \mathrm{~mW}$ is applied to the heater $(570 \mathrm{~mW}$ applied to the heater and leads), the valve flow rate switches in $1.1 \mathrm{~s}(90 \%-10 \%)$, with a leak rate of $2.2 \times 10^{-3} \mathrm{sccm}$. Pressure across the valve flow path was $530 \mathrm{~Pa}$ when open and $115 \mathrm{kPa}$ when closed. This results in an open-to-closed fluidic conductance ratio of nearly one million. 
Finally, with $250 \mathrm{~mW}$ applied to the heater ( $710 \mathrm{~mW}$ applied to the heater and leads), the valve switches from an initial flow rate of $1.1 \mathrm{sccm}$ in $430 \mathrm{~ms}(90 \%-10 \%$, after subtracting out the time constant of the test setup) as shown in Figure 5(c). Pressure across the valve flow path was $190 \mathrm{~Pa}$ when open and $20 \mathrm{kPa}$ when closed. The leak rate with $250 \mathrm{~mW}$ applied to the heater was to $1.4 \times 10^{-3} \mathrm{sccm}$.

Although a high power is required to close the valve quickly, a power of $90 \mathrm{~mW}$ applied to the elevated heater will hold the valve closed. Also, a lower hold power may be used if a higher leak rate can be tolerated in the application.

\subsection{Electrostatic Latch Results}

In testing of the electrostatic latch, as the latch voltage increased, the leak rate decreased. By applying up to $140 \mathrm{~V}$, the leak rate of the closed valve could be reduced by almost a factor of 2 (from $5.5 \times 10^{-3}$ to $3 \times 10^{-3} \mathrm{sccm}$ ). Breakdown of the insulator in the electrostatic latch occurred for voltages greater than $140 \mathrm{~V}$ prohibiting testing at higher voltages. In the second electrostatic latch test (see Section 2.3.4), a voltage of $140 \mathrm{~V}$ applied to the electrostatic latch enabled the applied pneumatic pressure to decrease from $270 \mathrm{kPa}$ to $190 \mathrm{kPa}$, or a decrease of $30 \%$. However, the latch could not hold the valve closed by itself.

\subsection{Discussion}

Relatively simple modifications to the present structure could improve the performance of the device substantially. First, the diaphragm should be thinned from $4.2 \mu \mathrm{m}$ to $3 \mu \mathrm{m}$ in order to reduce the spring constant of the diaphragm, thereby reducing the pressure required to close the device (from 270 to $130 \mathrm{kPa}$ ) and reducing the required electrostatic hold voltage. Next, all of the glass underneath the heater should be removed to maximize its thermal isolation. Additionally, the gold leads should be redesigned so that their resistance is negligible to the heater resistance after completion. This will eliminate inefficient heating of the valve substrate by the gold leads. Finally, the quality of the electrostatic latch insulator should be improved so that it can sustain applied voltages greater than $140 \mathrm{~V}$. With these improvements, a valve with the same flow and leak properties as before but capable of closing in $140 \mathrm{~ms}$ at $250 \mathrm{~mW}$, requiring a hold power of $20 \mathrm{~mW}$ without the electrostatic latch, and negligible hold power with an electrostatic voltage of $175 \mathrm{~V}$. Small increases in diaphragm diameter and increasing the depth and number of the diaphragm corrugations would also lead to improved performance as would increasing the electrostatic contact area.

\section{Conclusions}

This paper has presented a microvalve that combines thermopneumatic actuation for large force with electrostatic latching for low hold power. A built-in capacitive sensor allows closed-loop control of valve plate position. Although complete electrostatic latching was not achieved, the paper provides theory and guidelines to understand the performance limits to achieve an optimized device. It further demonstrates that hybrid actuators, when designed appropriately, may be utilized to eliminate the drawbacks of each stand-alone technology. 


\section{Acknowledgments}

The authors would like to thank Jay Mitchell for his advice and assistance with the design of the Au-Si eutectic bonding technology. This work was supported by the Engineering Research Centers Program of the National Science Foundation under Award Number EEC-9986866.

\section{References}

1. Shoji, S.; Esashi, M. Micro flow devices. In Proceedings of the 5th International Symposium on Micro Machine and Human Science, Nagoya, Japan, October 1994; pp. 89-95.

2. Oh, K.W.; Ahn, C.H. A review of microvalves. J. Micromech. Microeng. 2006, 16, R13-R39.

3. Bosch, D.; Heimhofer, B.; Muck, G.; Seidel, H.; Thumser, U.; Welser, W. A silicon microvalve with combined electromagnetic/electrostatic actuation. Sens. Actuat. A 1993, 37-38, 684-692.

4. Wagner, B.; Quenzer, M.; Hoerschelmann, S.; Lisec, T.; Juerss, M. Bistable microvalve with pneumatically coupled membranes. In Proceedings of the 9th Annual International Workshop on Micro Electro Mechanical Systems (MEMS), San Diego, CA, USA, February 1996; pp. 384-388.

5. Capanu, J.G.; Boyd, J.G., IV.; Hesketh, P.J. Design, fabrication, and testing of a bistable electromagnetically actuated microvalve. JMEMS 2000, 9, 181-189.

6. Frank, J.A.; Pisano, A.P. A low-power, low-leakage, bi-stable planar electrolysis micro gate valve. In Proceedings of the Solid-State Sensor, Actuator and Microsystems Workshop, Hilton Head, SC, USA, June 2004; pp. 156-159.

7. Shaikh, K.A.; Li, S.; Liu, C. Development of a latchable microvalve employing a low-meltingtemperature metal alloy. JMEMS 2008, 17, 1195-1203.

8. Yang, E.; Lee, C.; Mueller, J. Normally-Closed, Leak-tight piezoelectric microvalve under ultra-high upstream pressure for integrated micropropulsion. In Proceedings of the IEEE 16th Annual Conference on Micro Electro Mechanical Systems, Kyoto, Japan, 19-23 January 2003; pp. 80-83.

9. Sihler, J.; Slocum, A.; Lang, J. An electrostatically actuated low-leakage silicon microvalve. In Proceedings of the Solid-State Sensor, Actuator, and Microsystems Workshop, Hilton Head, SC, USA, 2004; pp. 282-285.

10. Rich, C.A.; Wise, K.D. A high-flow thermopneumatic microvalve with improved efficiency and integrated state sensing. JMEMS 2003, 12, 201-208.

11. Robertson, J.K.; Wise, K.D. A nested electrostatically-actuated microvalve for an integrated microflow controller. In Proceedings of the IEEE Workshop on Micro Electro Mechanical Systems (MEMS), Oiso, Japan, January 1994; pp. 7-12.

12. Bergstrom, P.L.; Li, J.; Liu, Y.; Kaviany, M.; Wise, K.D. Thermally driven phase-change microactuation. JMEMS 1995, 4, 10-17.

13. Henning, A.K.; Fitch, J.; Hopkins, D.; Lilly, L.; Faeth, R.; Falsken, E.; Zdeblick, M. A thermopneumatically actuated microvalve for liquid expansion and proportional control. In Proceedings of the International Conference on Solid State Sensors and Actuators (Transducers), Chicago, IL, USA, June 1997; Volume 2, pp. 825-828.

14. Potkay, J.A.; Wise, K.D. An electrostatically latching thermopneumatic microvalve with closed-loop position sensing. In Proceedings of the IEEE Workshop on Micro Electro Mechanical Systems (MEMS), Miami, FL, USA, January 2005; pp. 415-418. 
15. Haringx, J.A. Design of corrugated diaphragms. ASME Trans. 1957, 79, 54-65.

16. Renhuai, L.D. Nonlinear analysis of corrugated annular plates under compound load. Sci. Sin. Ser. A 1985, 27, 959.

17. Chau, H.L.; Wise, K.D. Scaling limits in batch-fabricated silicon pressure sensors. IEEE Trans. Electron Devices 1987, 34, 850-858.

18. Mitchell, J.S.; Najafi, K. A detailed study of yield and reliability for vacuum packages fabricated in a wafer-level Au-Si eutectic bonding process. In Proceedings of the 15th International Conference on Solid-State Sensors, Actuators and Microsystems (Transducers), Denver, CO, USA, June 2009; pp. 841-844.

(C) 2012 by the authors; licensee MDPI, Basel, Switzerland. This article is an open access article distributed under the terms and conditions of the Creative Commons Attribution license (http://creativecommons.org/licenses/by/3.0/). 